\title{
NOTAS SOBRE GRAMSCI E AS CIÊNCIAS SOCIAIS
}

\section{Renato Ortiz}

Não é minha intenção neste texto breve elaborar uma interpretação abrangente e exaustiva da obra de Gramsci. Vários autores já o fizeram; creio ainda, neste âmbito, que minha contribuição seria de pouca utilidade. Meu ponto de partida é outro, e construo-o a partir de uma pergunta: $\mathrm{O}$ que um cientista social pode atualmente retirar da leitura de sua obra? Trata-se, portanto, de um ângulo unilateral e interessado. Ele deixa de lado uma análise acurada dos conceitos e privilegia a relação do autor com o universo das ciências sociais. "Seria Gramsci um sociólogo?", "Um cientista político?", penso que esse tipo de questão leva a formular um conjunto de falsos problemas, pois, como marxista e militante, suas preocupações transbordavam as fronteiras disciplinares e tinham como referência direta o campo da prática política. Contudo, a inda-

Artigo recebido em julho/2006

Aprovado em agosto/2006 gação que subjaz este ensaio tem alguma razão de ser, sempre tive um fascínio por seus escritos. No final dos anos de 1970 estudei sistematicamente os Quaderni del carcere, o que me estimulou a escrever alguns estudos publicados em meu livro $A$ consciência fragmentada. Entretanto, chamava-me menos a atenção a perspectiva propriamente política (partido, revolução ou reforma, Estado, força e consenso), do que o esforço argumentativo do autor que expressava uma poderosa mente analítica capaz de formular e apreender uma série de problemas sociológicos. Isso me conduziu a comparar sua abordagem sobre a problemática da religião à de Max Weber. Retomo, assim, uma intuição antiga, procurando agora, num momento distinto de minha vida e da história das sociedades, dar-lhe forma e consistência.

Ao se defrontar com a obra gramsciana, o leitor dificilmente escapará de uma sensação insistente: trata-se de um pensamento datado. Vários elementos confirmam essa dimensão. Primeiro, é 
claro, a questão do socialismo, que vinha marcada pelo clima do final do século XIX e início do XX, no qual uma utopia de transformação radical sintetizava uma esperança coletiva. Era um momento de efervescência Revolução russa, consolidação das organizações de massa, emergência dos partidos comunistas - muito distinto da atmosfera contemporânea - fim do regime soviético, queda do muro de Berlim, declínio dos partidos comunistas, esgotamento da Guerra Fria. O debate sobre o socialismo não era, entretanto, mera controvérsia ideológica, tinha desdobramentos no plano teórico e muitos acreditavam que o marxismo, por estar associado ao devir histórico, desfrutaria de uma posição privilegiada, "superior", em relação a todas as outras interpretações possíveis da sociedade (as ideologias ou as ciências sociais). Outro aspecto diz respeito ao nacional-popular, ou seja, a construção da nação italiana, o que não implica uma temática especificamente gramsciana, pois esse tema era partilhado pela grande maioria dos intelectuais de seu tempo. Como a Itália é uma nação que se constituiu tardiamente, a discussão girava em torno da emergência de uma classe dirigente capaz de organizar e governar a população de um determinado território. As análises de Gramsci, diferentemente das de seus contemporâneos, sublinhavam a separação entre os intelectuais e o povo (da cultura à política), mas pressupunham também a possibilidade de integração dessas partes distantes. A filosofia da práxis, na sua imanência - termo caro ao autor-, coincidiria portanto com a realização do projeto nacional, distinto de outros, como o projeto liberal ou o facista, mas era assim mesmo nacional. Em tempos de globalização dificilmente essa discussão poderia ser contemplada da maneira como foi anteriormente. Há ainda a problemática da modernidade. Não se pode esquecer que a Revolução Industrial, ao lado do processo de unificação nacional, estava ainda em curso na Itália do início do século XX. Uma das formas de se captar de maneira emblemática os impasses dessa situação é por meio da metáfora corrente: questione meridionale. Gramsci escreve num período em que o país se moderniza e se encontra clivado pelas forças tradicionais e conservadoras (Igreja católica), no qual a industrialização é um elemento dinâmico na formação da nova classe operária. A oposição entre o norte industrializado e o sul agrário é simultaneamente um descompasso econômico e uma negação do ideal de integração nacional. Situação inteiramente distinta dos dias de hoje, em que a modernidade é uma realidade insofismável e o destino nacional redefine-se no seio da Comunidade Européia. Por fim, o tema do partido. Gramsci faz parte de uma geração que acreditava que a política, e mais propriamente o partido, tem uma função especifica, qual seja, a de "encantamento do mundo". Em outras palavras, o partido teria a capacidade de compreender e organizar coletivamente as vontades individuais. Sua organicidade estaria calcada em valores partilhados por todos e conseguiria, inclusive, orientar a conduta das pessoas. A filosofia da práxis, como interpretação abrangente e coerente do mundo, fundada na imanência da história, apresentava-se, assim, como uma ideologia positiva. O partido seria o Príncipe dos tempos modernos, o centro de irradiação de uma "grande narrativa", apreenderia o mundo na sua totalidade, ressignificando-o e conferindo-lhe inteligibilidade. Essa crença na capacidade da política (e Gramsci dedica inúmeras passagens para diferenciá-la da religião) certamente se rompeu. No texto seminal de Octávio Ianni, O príncipe eletrônico - um diálogo com Gramsci e Maquiavel -, constatamos que no mundo contemporâneo o papel que cabia ao partido, de organizador da vontade coletiva, em parte se esgotou (não inteiramente) e se restringiu; que uma outra dimensão social, a mídia e o universo do entretenimento, deslocou sua primazia anterior.

Entretanto, nos debates acadêmicos muitas vezes confunde-se "datado" com "ultrapassado". Os campos semânticos dessas duas qualidades são, porém, distintos. A noção de ultrapassado sugere algo definitivo e sua reiteração nos remete ao anacronismo. É possível dizer que nas ciências sociais muitas idéias estão realmente ultrapassadas. No domínio do conhecimento, isso fica patente. Por exemplo, as descobertas arqueológicas sobre a origem dos homíneos tornam incongruentes as concepções que tínhamos, ainda no século XIX, a esse respeito. Podemos retornar a elas quando fazemos uma história das idéias, mas seria insensato procurar aplicá-las à pesquisa arqueológica em curso. Relembro uma frase de Finley quando escreve sobre o progresso na historiografia: "Todo historiador inevitavelmente sofre por ignorar o que acon- 
tecerá depois dele. Todo historiador, até o mais medíocre, tem, portanto, uma "experiência histórica" maior que a de seus predecessores, por mais destacados que estes tenham sido" (Finley, 1994, p. 5). O volume de dados acumulados, o aprimoramento das técnicas utilizadas permitem ao estudioso uma precisão (pelo menos em potencial) da qual não dispunham Tucídides ou Burckhardt. Conhecemos, mesmo os que não são historiadores profissionais, mais sobre o passado, pois muitas das informações disponíveis substituem outras, consideradas, agora, inadequadas. A noção de datado possui uma outra configuração. Ela não se circunscreve ao espaço da superação, de algo envelhecido pelo tempo, cuja validade teria se esgotado. Simplesmente quer dizer que o pensamento se encontra vinculado a um determinado contexto. Nesse sentido, todo pensamento sobre a sociedade é datado. Este é o dilema, e diria também o sabor, das ciências sociais - a impossibilidade de se construir categorias universais. No entanto, isso não nos impede de reler Maquiavel ou Toqueville, Adorno ou Mannheim, Malinowski ou Lévy-Strauss, uma vez que seus pensamentos, datados, são parte de uma interlocução constante. As obras de nossos antepassados (que não são necessariamente antigas) são matéria de releituras e fecundam a imaginação sociológica no presente. Dedicar-se a elas não é perda de tempo ou anacronismo, mas um exercício de aprimoramento da reflexão.

Um tema presente nos Cadernos do cárcere diz respeito à relação entre o indivíduo e a sociedade. Tomo como exemplo a política, que é um traço constante no diálogo entre Gramsci e Benedetto Croce. Croce, quando analisa o Estado, distingue entre uma dimensão "meramente política e amoral" (ou seja, funcional) e uma dimensão ética; para ele essas duas expressões coexistem no interior de uma unidade inseparável. Força e consenso (autoridade e liberdade, em seu jargão filosófico) são termos correlatos e não podem ser pensados de maneira dicotômica. O Estado não se reduz, assim, à mera dominação, ele contém um fundamento moral e nele inscreve-se a ética, a ação política. Nas palavras do autor:

No ato político, na busca de se realizar um determinado fim, tudo é mediado pela política, e dela não está excluída a moralidade e a religiosidade, as idéias, os sentimentos e as instituições morais e religiosas [...] o homem moral somente realiza sua moralidade agindo politicamente, aceitando a lógica da política (Croce, 1930, pp. 227-228).

Poderia citar inúmeras passagens em sua obra que revelam essa idéia, mas desejo apenas chamar a atenção para a proximidade entre seu pensamento e o de Gramsci, cujo interesse pela ética, pela concepção do Estado como força e consenso - elemento moral subjacente à política -, é conhecido por todos. Daí sua proposta de compreender o marxismo como uma reforma intelectual e moral. Há, porém, um ponto que os separa, qual seja, a definição de partido político. Croce, do ponto de vista abstrato, considera a política uma questão moral; entretanto, no âmbito pragmático ela assume, para ele, uma perspectiva individualizadora: "O problema político como problema prático é um problema de empreendimento, de invenção, de criação, e por isso um fato individual e pessoal", e acrescenta, "a união entre os indivíduos que sentem a necessidade e a tendência de se juntarem dá origem, na esfera político-econônica, às associações, às corporações, aos sindicatos, e na esfera ético-política, ao que chamamos de partidos políticos" (Idem, pp. 228, 236). À pergunta "O que deve fazer a Itália?", ele retruca "O que devo eu fazer?". Esta inversão na ordem das frases tem implicações de natureza teórica, pois o leva a conceber o partido como uma união de indivíduos, um conglomerado de vontades particulares. Daí a importância que se atribui aos líderes, isto é, seriam eles os condutores da ação ético-política. A crítica de Gramsci focaliza este ponto. O moderno Príncipe não é uma pessoa real, mas tampouco uma reunião de indivíduos. Trata-se de um "organismo, um elemento complexo da sociedade no qual já se tenha iniciado a concretização de uma vontade coletiva reconhecida e fundamentada parcialmente na ação" (Gramsci, 1975b, p. 6). Portanto, o partido representa e organiza um conjunto de relações difusas que o antecedem e o legitimam.

Essa discussão pode ser analisada dentro de duas perspectivas. Uma, mais imediata, inscreve-se no plano político: são autores que partilham ideologias antagônicas e tematizam um mesmo problema, o que certamente é verdadeiro. Outra, que eu 
denominaria sociológica: o que está em causa é a natureza das relações sociais. Isso é claramente expresso na idéia recorrente de organismo (a metáfora organicista aprisiona o pensamento de muitos autores). Uma passagem, relativa à pergunta, "O que é o homem?", é sugestiva a esse respeito. O autor está dialogando com a concepção católica de homem, na qual se pressupõe a existência de um indivíduo singular que entra em relação com os outros homens e com a natureza. Nesse sentido, existiria um "único homem" (ou uma natureza humana), núcleo a partir do qual se articula sua interação com o mundo exterior. Mas seria esta a resposta realmente convincente? Ignora-se que a noção de indivíduo nada tem de natural; ela emerge somente em determinado momento da história (como muitos intelectuais italianos, Gramsci crê que isso ocorra a partir do Renascimento). A categoria "individualismo", que alimenta muitas perspectivas filosóficas, é um produto histórico e dificilmente poderia ser projetada no passado como tendo validade universal. Outro aspecto vincula-se à concepção do que seria a sociedade. Afirma o autor: "O indivíduo não entra em relação com os outros homens por justaposição, mas organicamente, isto é, na medida em que passa a fazer parte de organismos, dos mais simples aos mais complexos" (Idem, 1978, p. 39). Portanto, o singular somente faz parte do gênero humano mediante relações sociais. Já não estamos restritos apenas à noção de partido político, mas de instituições sociais, no sentido amplo do termo. A concepção avançada entende que as relações sociais transcendem e definem os indivíduos e sugere uma aproximação ao pensamento durkheimiano. A sociedade é sui generis, encerra uma lógica própria que não pode ser reduzida à somatória ou à justaposição de seus membros. Não obstante, ao contrário de Durkheim, Gramsci não faz tabula rasa do indivíduo, ou seja, para ele, se o homem é resultado de um processo, sua ação modela e transforma o meio que o circunscreve.

É um lugar comum a afirmação de que o homem não pode ser concebido senão como vivendo em sociedade; todavia, não se extraem de tal afirmação todas as conseqüências necessárias, a saber, que uma determinada sociedade humana pressupõe uma determinada sociedade das coisas. $\mathrm{Na}$ verdade, até agora estes organismos supra-indivi- duais têm recebido uma significação mecanicista e determinista, daí a reação contra este ponto de vista. É necessário elaborar uma doutrina na qual todas essas relações sejam ativas e dinâmicas, fixando bem claramente que a sede dessa atividade é a consciência do homem individual que conhece, quer, admira, cria, [...] e do homem concebido não isoladamente, mas repleto de possibilidades oferecidas pelos outros homens e a sociedade das coisas (Idem, p. 41).

Essa passagem aponta para uma problemática constitutiva do discurso das ciências sociais, isto é, a relação entre indivíduo e sociedade. O fato social possui uma vida própria, como queria Durkheim, entretanto a ética individual não se resume apenas a uma acomodação ao dado objetivo que a transcende. Ela é dinâmica e ativa, dilema que reencontraremos em Bourdieu, Parsons e Sartre, quando discutem a teoria da ação.

De certa maneira é possível pensar a proposta de Gramsci como uma ponte entre Durkheim e Weber. Isso fica claro no trecho citado, mas há outros indícios. Tomo o caso da religião. Durkheim a considera sobretudo a partir da idéia de vínculo social. A religião constitui uma comunidade moral na qual seus membros participam (comungam) de um mesmo ideal. Ela gera solidariedade, aproximando as pessoas. Não é casual que um de seus discípulos, Maurice Halbwachs, tenha cunhado a noção de memória coletiva. Esta organiza as lembranças, ritualiza a crença, solda num mesmo grupo pessoas que dela fazem parte. Os estudos durkheimianos sobre as sociedades "primitivas" têm justamente o intuito de corrigir (dar outro rumo) sua análise anterior, na qual a divisão do trabalho era objeto central de sua preocupação. Nos textos mais tardios (nos quais já não mais se fala em solidariedade mecânica), o diálogo com a antropologia é privilegiado, e o universo da religião é pensado como consciência coletiva, abordagem que se estende também ao entendimento de um fenômeno moderno, a nação. Esta seria um todo integrado no qual os indivíduos partilhariam uma mesma memória coletiva. Weber toma outra direção. A religião encarna-se numa instituição - a igreja - que atua como uma "empresa de salvação das almas". Para compreendê-la seria necessário conhecer os meandros de sua doutrina, a organização do clero e a disputa entre visões e interesses 
distintos no quadro das crenças religiosas. Ao se referir a budismo ou bramanismo, Weber aborda os especialistas, porta-vozes e produtores de uma concepção intelectualizada de mundo: os sacerdotes. Daí sua particular atenção para com as heresias, as rupturas no interior de uma mesma ordem ideológica, e, evidentemente, sua relação com o poder de Estado. Exemplo disso é a reinterpretação que os levitas fazem do sacrifício no contexto da unificação do povo hebreu. Na sua luta contra o politeísmo - as crenças mágicas -, eles garantem o monopólio do sacrifício como exclusividade de um grupo que opera a partir do Estado, e, conseqüentemente, o legitima. Durkheim busca o que une; Weber, ao analisar os conflitos entre as diversas religiões (bramanismo versus budismo, catolicismo versus heresias, confucionismo versus taoísmo, sacerdotes versus mágicos) sublinha o que as separa

Gramsci está interessado nas duas dimensões. A religião, para ele, é uma concepção de mundo que interpreta a realidade (elabora uma versão), permite aos fiéis nela atuar segundo uma determinada ética, mas simultaneamente os agrega no interior da mesma comunidade. Essa idéia atravessa as páginas dos Cadernos do cárcere, sintetizada na afirmação de que o catolicismo é o "intelectual orgânico" da Idade Média. Como doutrina, é debatido e consagrado pelos teólogos, que, nesse sentido, contrapõem-se às heresias e à religiosidade dos "mais simples" (os monges não possuíam o mesmo tipo de formação teórica que os teólogos). Gramsci, como Weber, estuda em detalhe o papel dos intelectuais, seu cosmopolitismo (incentivado pelo papado) em relação à fragmentação do poder feudal, sua intolerância diante da ameaça herética à unidade da Igreja (São Francisco de Assis e o culto à pobreza). Entretanto, na qualidade de "orgânico", o catolicismo funcionaria também como uma espécie de cimento cultural entre os diversos setores de uma sociedade hierárquica. A religião integra o que se encontra separado, crivado por lutas de interesses e desavenças doutrinárias. Na verdade, a religião é uma parte de um capítulo mais amplo, a ideologia. Gramsci a considera uma Weltanschuung com um valor cognitivo, que interpreta o mundo ético, orienta a ação, mas também uma moral capaz de fundar um determinado tipo de solidariedade. Certamente, as ideologias possuem amplitude e potencialidades distintas - daí sua distinção entre filosofia e religião, ou entre religião e senso comum -, porém, todas podem ser pensadas a partir dessa mesma matriz teórica.

Suas análises têm implicações que podem ser consideradas tanto no interior da tradição marxista, como fora dela. Se a ideologia é pensada como um elemento cognitivo, uma concepção de mundo inerente à vida social, e se Gramsci descarta a idéia de natureza humana, a conclusão que se impõe é lógica: não há sociedade sem ideologia. Isso o aproxima de Althusser, quando afirma que o homem é um "animal ideológico" - não obstante os contrastes evidentes entre suas idéias, sobretudo em relação à concepção de ciência -, e de Lévy-Strauss, que o apreende como um "animal simbólico". Mas também de Bakhtin, que considera a linguagem um signo, sendo que todo signo é, para ele, ideológico. O simbólico seria, portanto, constitutivo dos seres vivendo em sociedade. Seria uma ilusão imaginarmos uma sociedade sem ideologia, pois é por meio dela que os homens tomam consciência de si mesmos, dos outros, e atuam no mundo. Justamente na passagem citada anteriormente, a respeito da "natureza humana", Gramsci insiste na relação ativa que os homens têm com a sociedade e a natureza; o homem age conscientemente e reage na sua interação com as coisas que o cercam (diríamos hoje, possui reflexividade). Nesse sentido, ideologia é poder, ou seja, capacidade que lhe permite atuar e modificar o mundo. A problemática do simbólico constitui, na verdade, uma mediação entre a perspectiva gramsciana e a antropologia, aproximando tradições intelectuais que se forjam em campos separados e distantes (cf. Durham, 2004). Está presente também numa corrente do marxismo inglês (Raymond Williams), marcando uma tendência que posteriormente irá desembocar nos estudos culturais. Essa convergência entre domínios distantes não é fortuita, mas está centrada num aspecto particular, qual seja, a importância atribuída às representações simbólicas na constituição dos indivíduos e da sociedade.

Há um outro aspecto que também remete à idéia de sociedade. Contrariamente a Lukács, que opera com categorias essencialistas, buscando uma ontologia do Ser, Gramsci é marcado pelo historicismo. O exemplo da religião é novamente sugestivo. Como concepção de mundo, a religião afasta-se da idéia de "alienação" ou de "falsa cons- 
ciência" para ser apreendida como ideologia encarnada na história. Em alguns momentos, durante a Idade Média, o catolicismo possui um valor altamente positivo, é "orgânico", tece um vínculo social entre as classes e os grupos sociais. Em outros, no período de constituição da moderna Itália, ele se torna "tradicional" ao perder sua função de solidariedade, e atua como força reativa diante das mudanças em curso. A perspectiva gramsciana é herdeira de uma tradição filosófica que se distingue do idealismo alemão. Hegel pensava os conceitos na sua forma e conteúdo; sua mera afirmação abstrata era o início de uma história que ainda não tinha se realizado. Spaventa e De Sanctis, hegelianos do século XIX, nascidos na Itália, constroem sua obra com base no historicismo, pois estão imersos nas lutas políticas pela unificação do Estado nacional. Contrariamente aos jovens hegelianos alemães, o idealismo italiano vincula-se à realidade política e social do final do século XIX (cf. Piccone, 1977). Por isso o pensamento gramsciano dificilmente opera com a categoria "alienação", menos ainda com a idéia de essência das coisas sociais. A ideologia não pode ser pensada como falsa consciência, uma vez que, sendo constitutiva do animal simbólico homem, é o substrato no qual se funda sua humanidade.

Gramsci distancia-se também de uma interpretação francesa da obra de Hegel, que influenciou Franz Fanon e os intelectuais isebianos no Brasil. Fruto de uma leitura da dialética do senhor e do escravo, dos Manuscritos filosóficos de Marx, mesclada com o existencialismo de Sartre, essa concepção partia do conceito de alienação para compreender as questões de sua época - o colonialismo e a dependência dos países do Terceiro Mundo (cf. Ortiz, 1985). Tanto Fanon como os isebianos partem de um núcleo de categorias para entender a questão nacional: "Ser nacional", "autenticidade", "desalienação da consciência". Gramsci interessa-se pela mesma problemática, o bloco histórico e a nação italiana, mas em nenhum momento o trata como uma essência, um Ser cuja ontologia poderia ser revelada pelo pensamento. Mesmo quando procura diferenciar a "superioridade" da filosofia da práxis em relação às outras filosofias ou ideologias, sua argumentação evita uma aproximação ontológica. O marxismo é expressão das contradições históricas, sua verdade é "provisória", isto é, vincula- se a um determinado tempo. Não faz sentido, portanto, contrapô-lo às outras filosofias em termos de "verdadeiro" ou "falso", "real" ou "alienado". Tampouco é verossímil a dicotomia "ciência verdadeira" e "ciência burguesa", "pensamento autêntico" e "pensamento distorcido". Gramsci desconfia do "fanatismo pela ciência" que ele associa à superstição. Esse tipo de raciocínio somente pode existir quando postula a existência das coisas em si, cuja verdade se refletiria inteiramente, sem distorção, em apenas um tipo idealizado de apreensão do mundo. Esta não é apenas uma discussão de caráter filosófico, tem conseqüências também sociológicas. Com efeito, está-se pensando sociedade como um conjunto de forças, imersas na história e marcada por interesses diversos, o que nos afasta de qualquer tipo de visão essencialista, o que, atualmente, é muito comum quando se discute a problemática das identidades.

Retomo agora a pergunta interessada que deu origem a este ensaio. Nessa minha digressão, creio ter sido possível apontar alguns pontos que merecem ser sublinhados. O primeiro diz respeito ao conceito de hegemonia. Ele pode ser lido, como o foi no passado (penso no livro de Luciano Gruppi), numa perspectiva exclusivamente (ou quase) vinculada à esfera da política (relação com Lênin, bloco histórico, papel revolucionário do partido, Revolução de outubro etc.). Contudo, ele sugere também um outro caminho. A hegemonia não pode prescindir de determinadas concepções de mundo que o organizam cognitivamente, constroem referências simbólicas para a ação das pessoas e contrapõem-se a outras visões de mundo. Por isso, a política não se resume à esfera dos partidos ou do Estado, mas adentra o mundo da cultura. Em outros termos, a problemática do poder não se limita a um domínio da sociedade - a arte da política-, como se a estrutura desta realmente nela tivesse o seu núcleo ou a sua origem. Por isso Gramsci volta-se para temas diversos, como o jornalismo, a escola, a religião, a literatura. O corolário disso é que, mesmo quando falamos de política, no sentido estrito do termo, dificilmente a compreenderíamos inteiramente isolando-a dos elementos que, na verdade, não lhe são exteriores. Gramsci, nos critérios atuais de uma determinada ciência política, seria, felizmente, um mau cientista político, pois da mesma maneira que não aceita a 
idéia de um homo economicus, desvinculado das relações sociais que o constituem, ele se afasta da concepção de um homo politicus, especialista num determinado tipo de ação. As fronteiras da política não coincidem, portanto, com o território da disciplina ciência política.

O segundo aspecto remete à heterogeneidade e à diversidade interna das sociedades. A idéia de hegemonia não significa apenas linhas de força ou relações de poder. Isso é verdade, mas nela subjaz uma premissa, qual seja, a heterogeneidade social. No debate sobre cultura de massa (que, evidentemente, não é considerado por Gramsci, uma vez que em sua época os países europeus não sentiam ainda o peso e a importância das indústrias culturais) a dimensão da homogeneização impõe-se. O que se denomina "processo de massificação" supõe a existência de um único padrão cultural (em linguagem adorniana, a "mercadoria"). A sociedade uni-dimensional seria, assim, marcada pela unicidade das condutas e do pensamento. Também a perspectiva liberal (segundo o modelo de Edward Shills) fundamenta-se no mesmo princípio analítico, a saber, os meios de comunicação são "democratizadores" porque homogeneizam as desigualdades antes existentes. Não é minha intenção discutir cada uma dessas visões, mas sublinhar que, quando consideramos a cultura em termos de hegemonia, evitamos o dilema da homogeneização. Não se trata de pensar um único padrão de cultura ou de comportamento, mas de perceber que uma tendência dominante não extingue as diversas concepções de mundo que a ela se contrapõem. Gramsci permite ler as ideologias como matrizes de interpretação enraizadas em grupos sociais concretos e que sua diferenciação é uma expressão da própria organização social. Existem "filosofias" (entre elas a da práxis), religiões, senso comum (das religiões, ou das filosofias), folclore (manifestações fragmentadas da cultura popular). Além disso, uma mesma concepção de mundo conhece distintas variações. Por exemplo, a religião dos intelectuais e a religião dos "simples". Cada uma delas manifesta uma inflexão particular, uma maior racionalização entre os teólogos, uma adesão mais emotiva e menos intelectualizada entre as classes populares. Até mesmo o marxismo adapta-se a essa perspectiva. Para tornar-se hegemônico, ele necessitaria transformar-se em senso comum, porém, ao fazê-lo (caso isso fosse possível) permaneceria a clivagem entre o discurso dos especialistas - intelectuais orgânicos - e o restante da população. Deve-se ainda levar em consideração a situação de cada lugar, país ou região, pois uma mesma concepção de mundo se realiza historicamente de maneira diversificada (catolicismo italiano, protestantismo norte-americano etc.). Numa das notas dos Cadernos do cárcere, Gramsci se pergunta sobre a possível relação entre a unidade religiosa de um país e a multiplicidade de partidos, e vice-versa, a relativa unidade dos partidos e a proliferação de seitas religiosas e igrejas. Ele contempla três exemplos: os Estados Unidos, onde existem poucos partidos e uma plêiade de confissões religiosas; a França, conhecida por sua unidade religiosa e pela existência de dezenas de partidos; e a Rússia tzarista, onde os partidos praticamente inexistiam e a fragmentação religiosa era patente. Sua conclusão é sugestiva:

Todo homem tende a ter uma única concepção de mundo orgânica e sistemática, mas porque a diferenciação cultural é muito profunda a sociedade assume a forma de uma bizarra variação de correntes, apresentando um colorido religioso ou um colorido político segundo a tradição histórica (Gramsci, 1975c, p. 212).

Encontramos-nos, assim, distante da idéia de homogeneização. As sociedades, mesmo quando integradas a partir de padrões específicos (religioso ou político), são marcadas pela história e pelas diferenças e divisões sociais que encerram.

Retenho, por fim, uma categoria que para mim possui grande relevância nos estudos das sociedades. Creio mesmo que seu rendimento em pesquisas empíricas pode ser muitas vezes (nem sempre, é claro) valioso. Refiro-me à noção de intelectual. Na obra gramsciana, essa noção se desdobra em dois planos: o político e o religioso; são esses os níveis privilegiados pela análise. Evidentemente há uma preferência pelo domínio da política, afinal Gramsci é um militante com a intenção de transformar o mundo (o partido como "intelectual orgânico" na busca pela hegemonia da filosofia da práxis). Mas são inúmeros os exemplos sobre a religião em sua obra, não apenas sobre o catolicismo, por causa do embate entre os comunistas e 
a Igreja católica ou a aliança entre Mussolini e o Vaticano, eles se estendem também ao islamismo, à ética protestante e ao espírito capitalista. Nesse contexto, o intelectual é visto como um especialista dos universos simbólicos, capaz, dentro de uma instituição determinada (partido ou igreja), de formular uma interpretação coerente do mundo e de orientar a ação. Foi por isso que um historiador como Le Goff, ao escrever sobre os intelectuais na Idade Média (sem ter lido Gramsci), posteriormente, no prefácio da reedição de seu livro, presta-lhe uma grande homenagem (cf. Le Goff, 1988). Na verdade, a categoria é imprescindivel para se compreender um conjunto de questões relativas ao surgimento das universidades sob a égide da influência papal. O catolicismo é cosmopolita porque, ao falar em nome de um universal religioso, escapa ao controle provinciano das autoridades feudais. Para isso é necessário que os teólogos tematizem sua universalidade, procurando legitimá-la religiosa e politicamente. Algo semelhante ocorre quando discutimos o fundamentalismo islâmico, incompreensível sem o trabalho interpretativo realizado por intelectuais que o distinguem da visão tradicional dos ulemás e o ressignificam dentro de uma perspectiva que mescla a reinterpretação do passado, a releitura do Alcorão e as demandas do presente (cf. Kepel, 2000). A operação simbólica de significação dá inteligibilidade ao mundo e guia a conduta beligerante dos acólitos (por exemplo, a reinterpretação da noção de jihad, guerra santa). Existe ainda nos Cadernos do cárcere uma dimensão "menor" que pode ser apreendida por meio de uma série de considerações que formam, no interior da obra, um conjunto secundário de anotações. No entanto, elas são sugestivas e merecem ser levadas em conta. Quando se lê os Cadernos na sua versão integral, não em partes como foram publicados primeiramente, tem-se uma sensação estranha. Chama a atenção do leitor várias anotações, geralmente breves, dedicadas a assuntos aparentemente pouco expressivos. Muitas delas agrupam-se em torno da denominação "os netos do padre Bresciani" (um dos itens do livro Literatura e vida nacional) e referem-se a uma literatura de sacristia, isto é, publicações católicas populares nas quais não existem um refinamento maior do pensamento religioso ou filosófico - por exemplo, a revista Observatore, uma crítica de costumes em nada acadêmica ou científica, voltada para o conhecimento geral. Gramsci leva a sério essas publicações, debate com seus autores anônimos, interpela-os do ponto de vista filosófico e político. Por que se interessava por um material dessa natureza? Há, evidentemente, uma imposição de fato, uma vez que na prisão era o material disponível, mas Gramsci dele retira algumas lições. Os textos encerram uma explicação do mundo rente ao senso comum. Sem serem rebuscados, eles trabalham num patamar mais distante da racionalização coerente e articulada dos intelectuais e têm a função específica de estabelecer uma doxa, uma versão dos acontecimentos, constituindo-se pouco a pouco em "crença popular". Em outras palavras, deparamos-nos com instituições sociais capazes de reiterar e difundir uma determinada compreensão do mundo. Nas sociedades atuais existem espaços similares nos quais atuam esses intermediários simbólicos: jornais de bairro, livros bestsellers, literatura esotérica, comentários televisivos etc. Nessas publicações os problemas sociais são relatados e reinterpretados, matéria cotidiana que alimenta a reflexão e a ficção sobre a ordem das coisas. Compreendê-los ajuda-nos a sair da problemática da inteligentzia, das grandes explicações, imergindo-nos numa dimensão da vida social na qual há uma interação mútua entre os argumentos explicativos e o cotidiano.

\section{BIBLIOGRAFIA}

ALTHUSSER, Louis. (s.d.), Ideologia e aparelhos ideológicos de Estado. São Paulo, Martins Fontes.

BAKHTIN, Mikhail. (2004), Marxismo e filosofia da linguagem. São Paulo, Hucitec.

CROCE, Benedetto. (1930), Etica e politica. Bari, Laterza.

DURHAM, Eunice. (2004), A dinâmica da cultura. São Paulo, CosacNaify.

DURKHEIM, Émile. (1968), Les formes élementaires de la vie religieuse. Paris, PUF.

FINLEY, Moses. (1994), História antiga. São Paulo, Martins Fontes. 
GRAMSCI, Antonio. (1968a), Os intelectuais e a organização da cultura. Rio de Janeiro, Civilização Brasileira.

(1968b), Literatura e vida nacional. Rio de Janeiro, Civilização Brasileira.

(1975a), Quaderni del carcere. Torino, Einaudi.

(1975b), Note sul Machiavelli. Torino, Riuniti.

. (1975c), "Religione e politica", in Riuniti. , Passato e presente, Torino, (1978), Concepção dialética da bistória. Rio de Janeiro, Civilização Brasileira.

GRUPPI, Luciano. (1978), O conceito de hegemonia em Gramsci. Rio Janeiro, Graal.

IANNI, Octávio. (2001), "O príncipe eletrônico", in _. Enigmas da modernidademundo, Rio de Janeiro, Civilização Brasileira.

KEPEL, Gilles. (2000), Jihad: expansion et déclin de l'islamisme. Paris, Gallimard.

LE GOFF, Jacques. (1988), Os intelectuais na Idade Média. São Paulo, Brasiliense.

ORTIZ, Renato. (1980), "Gramsci/Weber: contribuição para uma teoria da religião", in , A consciência fragmentada, Rio de Janeiro, Paz e Terra.

. (1985), "Alienação e cultura", in Cultura brasileira e identidade nacional, São Paulo, Brasiliense.

PICCONE, Paul. (1977), "From Spaventa to Gramsci". Telos, 31, Spring.

WEBER, Max. (1968), The religion of China. Nova York, Free Press.

. (1967), The religion of India. Nova York, Free Press. 


\section{NOTAS SOBRE GRAMSCI E AS CIÊNCIAS SOCIAIS}

Renato Ortiz

Palavras-chave: Gramsci; Sociedade; Religião; Política; Hegemonia.

Este texto procura analisar a obra de Antonio Gramsci de uma perspectiva sociológica, ou melhor, o autor tem como premissa a pergunta: $O$ que um cientista social pode atualmente retirar da leitura de sua obra? Tratase, portanto, de um ângulo unilateral e interessado. A discussão proposta envolve problemáticas constitutivas do discurso das ciências sociais, no sentido de compreender como Gramsci considera a relação entre o indivíduo e a sociedade, passando por sua concepção de religião e de hegemonia.

\section{NOTES ON GRAMSCI AND SOCIAL SCIENCES}

Renato Ortiz

Keywords: Gramsci; Society; Religion; Politics; Hegemony.

This text aims at analyzing the work of Antonio Gramsci from a sociological perspective. The premise of the author addresses the question: What can a social scientist remove from the reading of his work? We, therefore, deal with a unilateral and implicated angle. The proposed discussion involves constituent problems regarding the treatment of the social sciences, in ways of understanding how Gramsci regards the relationship between the individual and society, going through its conception of religion and hegemony.

\section{NOTES À PROPOS DE GRAMSCI ET DES SCIENCES SOCIALES}

Renato Ortiz

Mots-clés: Gramsci; Société; Religion; Politique; Hégémonie.

Ce texte propose une analyse de l'œuvre de Antonio Gramsci sous une perspective sociologique ou, plutôt, en considérant comme prémisse la question suivante : qu'est-ce qu'un scientifique du domaine social peut extraire, actuellement, de la lecture de son œuvre ? Il s'agit, donc, d'un angle unilatéral et intéressé. La discussion proposée inclue des problèmes sur la construction du discours des sciences sociales, dans le sens de comprendre de quelle façon Gramsci considère la relation entre l'individu et la société, en passant par sa conception de religion et d'hégémonie. 